\title{
O processo de esvaziamento industrial em São Gonçalo no século XX: auge e declínio da "Manchester Fluminense"
}

\author{
Victor Leonardo de Araujo \\ Hildete Pereira de Melo*
}

\begin{abstract}
RESUMO
O artigo tem por objetivo descrever o processo de esvaziamento industrial do Município de São Gonçalo, localizado na Região Metropolitana do Estado do Rio de Janeiro. Outrora um dos mais importantes parques industriais do Estado - tendo recebido a alcunha de "Manchester Fluminense" - o processo de industrialização, construído de forma "espontânea" pelo setor privado, não teve fôlego e já na década de 1970 começaram a aparecer os primeiros sinais de sua decadência industrial. Entre as causas apontadas, a mais importante parece ter sido a negligência da ação estatal no município, nas três esferas, seja pela precariedade da infraestrutura, seja pela escolha de outras regiões fluminenses para abrigar investimentos estatais de maior fôlego, deslocando para essas regiões o dinamismo industrial do Estado.
\end{abstract}

Palavras-chave: São Gonçalo, esvaziamento industrial, economia fluminense

\begin{abstract}
The paper aims to describe the de-industrialization process occurred in São Gonçalo, located in the metropolitan area in Rio de Janeiro. In the past, it was one of the most industrialized town in Rio de Janeiro' State, so called "Manchester Fluminense". Yet in 1970 appeared the early signs of its decay. Among the leading causes, we can mention the negligence of the three levels of government, because of the poor infrastructure, and the unequal distribution of state investments among the cities at the expense of the metropolitan region.
\end{abstract}

Keywords: São Gonçalo; Industry Drain; Rio de Janeiro State Economy

\footnotetext{
*Victor Leonardo de Araujo: Professor Adjunto da Faculdade de Economia da UFF. E-mail: victor_araujo@terra.com.br.

Hildete Pereira de Melo: Professora Associada da Faculdade de Economia da UFF. E-mail: hildete43@gmail.com.
} 


\section{Introdução}

Até meados do século XX, o Município de São Gonçalo constituía um dos mais importantes distritos industriais do antigo Estado do Rio de Janeiro. O processo de industrialização, iniciado de forma "espontânea" pelo setor privado a partir de incentivos oferecidos pelo governo estadual, rendeu ao município um parque industrial e também a alcunha de "Manchester Fluminense", em comparação à famosa cidade industrial britânica. Entretanto, o fôlego da indústria gonçalense durou pouco e, desde a década de 1970, o município já não figura entre os mais industrializados do Estado, mesmo se a base de comparação for o território do antigo Estado do Rio de Janeiro, antes da fusão com a Guanabara.

Este artigo tem por objetivo apontar as principais causas das fases de auge e declínio da indústria gonçalense. Depois da presente introdução, será traçado um panorama da indústria fluminense, cenário e território onde se situa o Município de São Gonçalo, na seção um. A segunda seção discutirá a fase de industrialização gonçalense, ao passo que a terceira seção discutirá o seu declínio. A quarta seção fará algumas considerações sobre a indústria gonçalense na passagem de século, bem como algumas perspectivas para a primeira década dos anos 2000. A última seção fará as considerações finais.

\section{A indústria fluminense no século $X X$ : um panorama}

Embora tenha sido o berço da industrialização brasileira, a indústria fluminense sofre desde a década de 1930 um inexorável processo de esvaziamento industrial, perdendo posição para a indústria paulista (Araujo, 2005).

Capital do Império e da República a partir de 1889, a cidade do Rio de Janeiro reunia em seu território os requisitos necessários ao surgimento da atividade industrial: concentração do capital mercantil, infraestrutura adequada, gasto público como importante componente da demanda e disponibilidade de mão de obra (Melo e Considera, 1986). Entretanto, já no primeiro quarto do século $\mathrm{XX}$ a indústria paulista registrava crescimento mais acelerado do que a fluminense. A atividade cafeeira permitiu não somente a acumulação de capitais necessária para o processo de desenvolvimento industrial paulista, como também a formação de um mercado de trabalho de maiores dimensões que o fluminense e que, por isso mesmo, oferecia oportunidades para que a indústria paulista operasse com um menor custo da mão de 
obra (Cano, 1977). O território fluminense, por seu turno, não conseguia dar sustentação ao seu processo de desenvolvimento industrial. Na capital, o processo de acumulação de capitais dava-se a partir do setor mercantil, ao passo que, no interior - o assim chamado antigo Estado do Rio de Janeiro -, a acumulação ocorria por meio do setor cafeeiro, já em decadência (Melo e Considera, 1986; Pignaton, 1977). Os dois tipos de processo de acumulação - na capital, atrelado ao setor mercantil e, no interior, atrelado ao setor cafeeiro decadente - eram incapazes de dar sustentação a um ritmo mais acelerado de desenvolvimento industrial.

Já na década de 1940 a cidade do Rio de Janeiro deixava de despontar como importante vetor de desenvolvimento industrial, cedendo participação relativa para o interior do Estado, de sorte que dois importantes investimentos estatais resultaram na Companhia Siderúrgica Nacional (CSN), situada no então Município de Barra Mansa, ${ }^{1}$ e a Fábrica Nacional de Motores (FNM), em Duque de Caixas. Isto não significa, entretanto, que o interior reunisse as condições absolutamente adequadas para abrigar novas indústrias. A industrialização por substituição de importações, intensificada a partir da década de 1950 com estímulos deliberados do Estado brasileiro, requeria plantas de maior porte. As áreas disponíveis na cidade do Rio estavam saturadas, ao passo que a infraestrutura do interior mostrava-se precária para receber os novos investimentos industriais (IEPS, 1983). A indústria fluminense seguiu seu curso de perda relativa durante o Programa de Metas, que, ao eleger a indústria automobilística como setor-chave da nova fase da industrialização, acabou por beneficiar o desenvolvimento industrial no Estado de São Paulo (Araujo, 2005), muito embora o Rio ainda tenha se beneficiado dos estímulos da construção de refinarias (Melo e Considera, 1986).

A transferência da capital federal para a região Centro-Oeste, após a conclusão da construção de Brasília, dando à cidade do Rio de Janeiro status de Estado da Guanabara, deu prosseguimento ao processo de esvaziamento industrial fluminense, muito embora, como salienta Araujo (2005), a perda da condição de capital federal não fosse a causa do processo. De fato, o processo de esvaziamento vem do início do século XX; como mostra a Tabela 1, já em 1950 a participação do Rio de Janeiro, somada com a do Distrito Federal, correspondia a menos da metade da participação de São Paulo na produção industrial brasileira. Ainda assim, a mudança da capital federal teve óbvios impactos econômicos negativos para o Rio de Janeiro, pela perda de parte ${ }^{2}$ da componente de demanda constituída pelo gasto público.

\footnotetext{
${ }^{1}$ O Município de Barra Mansa iria se desdobrar posteriormente em dois, constituindo-se o Município de Volta Redonda.

${ }^{2} \mathrm{O}$ processo de transferência do setor público federal do Rio de Janeiro para Brasília foi gradual.
} 
Tabela 1. Rio de Janeiro e São Paulo: participação percentual na produção industrial brasileira $(\%)-1950$ a 2000

\begin{tabular}{|l|l|l|l|l|l|l|l|}
\hline Estados & $\mathbf{1 9 5 0}$ & $\mathbf{1 9 6 0}$ & $\mathbf{1 9 7 0}$ & $\mathbf{1 9 7 5}$ & $\mathbf{1 9 8 0}$ & $\mathbf{1 9 8 5}$ & $\mathbf{2 0 0 0}$ \\
\hline SP & 46,6 & 54,5 & 58,1 & 55,9 & 53,4 & 51,9 & 42,0 \\
\hline RJ* & 21,1 & 17,3 & 15,7 & 13,5 & 10,6 & 9,5 & 8,6 \\
\hline
\end{tabular}

*Soma da cidade do Rio de Janeiro (antigo Distrito Federal) com o Estado do Rio de Janeiro. Fonte: Araujo (2005:9).

A primeira metade da década de 1960 foi marcada por turbulências de natureza política que rebateram na esfera econômica, resultando em baixo crescimento do PIB, e em adiamento das fases posteriores do processo de industrialização por substituição de importações. Somente ao fim desta década, com o assim chamado Milagre Econômico, a economia brasileira voltou a despontar e a indústria paulista atinge o seu ápice em termos de participação relativa em 1970. O II Plano Nacional de Desenvolvimento (II PND), implementado na década seguinte, previa uma ação deliberada do Estado brasileiro com o intuito de promover a desconcentração econômica regional, particularmente "evitar a tendência à concentração da atividade industrial na área metropolitana paulista, perseguindo um equilíbrio no triângulo São Paulo-Rio-Belo Horizonte” (Lessa, 1998:24).

Foi no âmbito do II PND que se forjou a fusão entre os Estados da Guanabara e do Rio de Janeiro. A fusão seria capaz de resolver velhos problemas, sendo o principal deles a dificuldade histórica em integrar uma mesma região metropolitana sob duas administrações estaduais distintas. $\mathrm{O}$ antigo Estado do Rio de Janeiro colheria os benefícios de ter, aplicadas sobre o seu território, receitas tributárias antes restritas à antiga capital. Mas esta distribuição, se ocorresse de fato, seria considerada ônus à cidade do Rio. Niterói, por seu turno, perderia o status de capital de Estado e também teria de lidar com o risco de esvaziamento econômico. Ao término da década de 1970, a indústria fluminense correspondia a apenas pouco mais de 10\% da indústria nacional. Segundo Diniz (1991), durante esta década, somente três estados registraram perda de participação: São Paulo, Pernambuco e Rio de Janeiro.

A estagnação econômica das décadas de 1980 e 1990 foi particularmente onerosa para a indústria fluminense. Essencialmente voltada para o mercado interno (Melo e Alveal, 1988), o parque industrial fluminense sofreu os efeitos do ajuste recessivo implementado ao longo da década. A estratégia de crescimento liderado pelas exportações privilegiou os estados exportadores, relegando ao Rio a continuidade da trajetória de declínio industrial. A estratégia macroeconômica implementada nos anos 1990 também não foi capaz de provocar inflexões 
nessa trajetória: o câmbio sobrevalorizado e a abertura comercial foram particularmente onerosos para a indústria paulista, e a continuidade da estagnação da renda nacional não permitiu novos saltos para a indústria fluminense, a não ser pelo novo fôlego dado, já ao final da década de 1990, pela instalação da indústria automobilística (Peugeot e Volkswagen) na região do Médio Paraíba.

\section{O processo de industrialização de São Gonçalo}

Município emancipado de Niterói em 1890, e por isso mesmo parte da periferia do antigo Estado do Rio, não se poderia esperar dele posição de destaque no surto inicial da industrialização brasileira. De fato, até a década de 1930 a economia gonçalense era essencialmente agrícola. A produção de gêneros agrícolas era beneficiada com a existência de inúmeros pequenos portos, o que facilitava o escoamento da produção. ${ }^{3}$ Com localização geográfica privilegiada, na entrada da Baía de Guanabara, São Gonçalo ainda exercia um papel importante servindo como elo de ligação com o interior da Província do Rio de Janeiro. Esse importante fator locacional foi reconhecido quando da construção do ramal ferroviário da Estrada de Ferro Cantagalo (atual Leopoldina), em 1870, que cortava todo o município e facilitava o escoamento da produção dos gêneros agrícolas produzidos em seu território.

Levou tempo até que o governo da Província do Rio de Janeiro reconhecesse a necessidade de estímulos específicos no sentido de promover a atividade industrial, diferentemente da atividade agrícola, para a qual existia, em 1929, o Instituto de Fomento e Economia Agrícola, vinculado à Secretaria de Finanças do Estado. Não havia nenhum órgão semelhante voltado para o desenvolvimento do setor fabril. Ainda assim, as finanças públicas estaduais beneficiavam-se da arrecadação de impostos ligados à atividade industrial.

Em 11 de novembro de 1925 foi publicada uma legislação estadual, a Lei 1.991, que concedia benefícios fiscais às duas primeiras empresas que se instalassem no Estado no prazo de quatro anos. Tais benefícios consistiam em isenção de impostos estaduais, e facilidades na desapropriação e aquisição dos terrenos, e eram válidos para os setores de siderurgia, exploração e fabricação de cimento e moagem de trigo (Oliveira Junior, 1929). O município de São Gonçalo foi beneficiado com essa lei, por intermédio da qual se instalou no município, em 1926, a Companhia Brasileira de Usinas Metallurgicas, que no ano de 1929 produziu 3,9 toneladas de aço.

\footnotetext{
${ }^{3}$ Ver Palmier (1940) e Braga (1997).
} 
O [antigo] Estado do Rio de Janeiro continuou, assim, com os favores da Lei 1991, de 11 de novembro de 1925, a contribuir em prol do desenvolvimento da grande indústria que no Brasil deverá tomar o maior incremento, dadas as suas formidáveis reservas de minério de primeira qualidade, tanto de ferro como de manganês. (Rio de Janeiro (Estado), 1929:226)

A referida usina abastecia-se de ferros de guza provenientes de Morro Grande, em Minas Gerais, sendo que "o aço obtido na fábrica [era] genuinamente nacional, e até o revestimento do forno [era] feito com material refratário de primeira qualidade, confeccionado no município de São Gonçalo" (Rio de Janeiro (Estado), 1930:176).

A crise mundial de 1929 afetou em cheio a indústria nacional, voltando a recuperar-se em meados dos anos 30. Antes da recuperação, em 1931, São Gonçalo passou a abrigar a Cia Nacional de Cimentos Portland, próxima às jazidas de calcário disponíveis no município e descobertas "após um esforço de prospecção extensivo e custoso durante um período de muitos anos" (Phelp, 1969, ${ }^{4}$ apud Prochnik, 1984:217). De fato, para este tipo de indústria a disponibilidade de matérias-primas constitui um determinante fator locacional: ${ }^{5}$ a referida companhia de cimentos localizava-se próxima à mina de calcário de São José em Itaboraí, e também situava-se próxima do mercado consumidor (IBGE, 1957).

No ano de 1933, a Cia Brasileira de Indústrias Metallurgicas inaugura a maior oficina de laminação da América Latina (Rio de Janeiro (Estado), 1935:28). No mesmo ano, foi fundada, também em São Gonçalo, a Eletroquímica Fluminense, por intermédio de outra lei federal destinada a impulsionar a industrialização, o decreto 12.021 de março de 1928. Segundo este decreto, "o governo fazia concessões e dava auxílio pecuniário às três primeiras fábricas que se instalassem no país usando o processo hidroelétrico” (Braga, 1997:125). Além dos benefícios fiscais envolvidos em sua instalação, a localização em São Gonçalo devia-se a fatores específicos do local, tais como a proximidade com a zona salineira, "água e luz em abundância, e sediada nas principais vias de comunicação com os centros industriais compradores do seu produto, como o Rio de Janeiro e São Paulo" ( $O$ São Gonçalo, 21/11/91:23).

Outro aspecto em que se manifesta o dinamismo da atividade econômica é o fiscal. Particularmente no caso da indústria, a mensagem enviada pelo governo estadual à

\footnotetext{
${ }^{4}$ PHELP, D. M. Migration of industry to South America. New York: Green Wood, 1969.

5 "Como a argila é encontrada facilmente, as fábricas [de cimento] se localizam, em geral, junto às jazidas de calcário, para minimizar os custos de transporte” (Prochnik, 1984:211).
} 
Assembleia Legislativa em 1929 revela, ainda que brevemente, que "a enorme renda que aos cofres federais é dada pelos impostos de consumo de produtos industriais fabricados no Estado revela uma situação de primeira ordem para o Rio de Janeiro" (Rio de Janeiro (Estado), 1929:17). No ano de 1928, dentre as coletorias espalhadas pelos diversos municípios do Estado do Rio, as de São Gonçalo lideravam a arrecadação. Segundo Varsano (1997), o imposto de exportações - tanto para o exterior como para outros Estados - era a principal fonte de receita dos estados, enquanto a principal fonte de receita dos municípios era o imposto sobre indústrias e profissões. Somente a partir de 1934 passou-se a repartir a receita de impostos entre as diferentes esferas de governo, cabendo aos municípios de origem $20 \%$ da arrecadação. Em 1939, a renda obtida pelas coletorias localizadas no Município de São Gonçalo já era a maior do país: "S. Gonçalo fica em primeiro lugar entre as coletorias estaduais, em primeiro quanto às subcoletorias e agências e ainda em situação superior quanto a outras coletorias do Estado" (O Fluminense, 01/09/39:1).

São Gonçalo chega ao início dos anos 1940, quando do cinquentenário de sua emancipação política, como um dos municípios mais relevantes do antigo Estado do Rio de Janeiro, do ponto de vista da atividade industrial, possuindo o $2^{\circ}$ maior produto industrial do estado, perdendo apenas para Petrópolis, e com participação relativa semelhante à de Niterói (capital do antigo Estado do Rio) e de Campos, que àquela época também constituíam importantes parques industriais (Tabela 2). Já no ranking do emprego industrial, São Gonçalo também ocupava as primeiras colocações. A Tabela 2 exibe esses valores, considerando a atual configuração territorial fluminense - ou seja, a soma da cidade do Rio de Janeiro (antigo Distrito Federal) com o território do antigo Estado do Rio de Janeiro.

Tabela 2. Produto e emprego industrial (\%) por município do Estado do Rio de Janeiro (municípios selecionados) - 1940 e 1950

\begin{tabular}{l|l|r|l|r|l|r|l|r}
\hline & \multicolumn{4}{|c|}{ Produto } & \multicolumn{5}{c}{ Emprego } \\
\hline & 1940 & & 1950 & & 1940 & & 1950 & \\
\hline 1 & Rio de Janeiro & 66,91 & Rio de Janeiro & 70,15 & Rio de Janeiro & 73,39 & Rio de Janeiro & 66,54 \\
\hline 2 & Petrópolis & 4,47 & Barra Mansa & 6,56 & Niterói & 4,35 & Niterói & 5,80 \\
\hline 3 & São Gonçalo & 4,21 & Niterói & 3,87 & Petrópolis & 4,00 & Petrópolis & 4,25 \\
\hline 4 & Niterói & 3,90 & Petrópolis & 3,31 & Campos & 3,14 & Campos & 3,45 \\
\hline 5 & Campos & 3,85 & São Gonçalo & 2,84 & Magé & 1,78 & São Gonçalo & 2,62 \\
\hline 6 & Nova lguaçu & 2,25 & Campos & 2,77 & São Gonçalo & 1,73 & Barra Mansa & 2,17 \\
\hline
\end{tabular}




\begin{tabular}{l|l|r|l|r|l|r|l|r}
\hline 7 & Barra do Piraí & 2,19 & Nova Iguaçu & 0,92 & Nova Friburgo & 1,61 & Magé & 1,83 \\
\hline 8 & Nova Friburgo & 1,50 & Barra do Piraí & 0,90 & Nova Iguaçu & 1,52 & Nova Friburgo & 1,48 \\
\hline 9 & Barra Mansa & 1,41 & Duque de Caxias & 0,82 & Barra do Piraí & 0,89 & Duque de Caxias & 1,30 \\
\hline 10 & Piraí & 1,09 & Nova Friburgo & 0,75 & Barra Mansa & 0,84 & Nova Iguaçu & 1,27 \\
\hline & Total & 91,78 & Total & 92,89 & Total & 93,25 & & 90,71 \\
\hline
\end{tabular}

Fonte: IBGE, Censos econômicos dos Municípios - indústria, comércio e serviços, elaboração própria.

Uma proxy da produtividade pode ser calculada dividindo-se a participação relativa do produto industrial pela participação relativa do emprego industrial apresentadas na Tabela 2. Com base neste indicador, a indústria gonçalense era a mais produtiva considerando-se apenas os municípios com maior parque industrial (Gráfico 1). ${ }^{6}$

\section{Gráfico 1. Produtividade da indústria nos nove maiores produtores industriais do Estado do Rio de Janeiro - 1940}

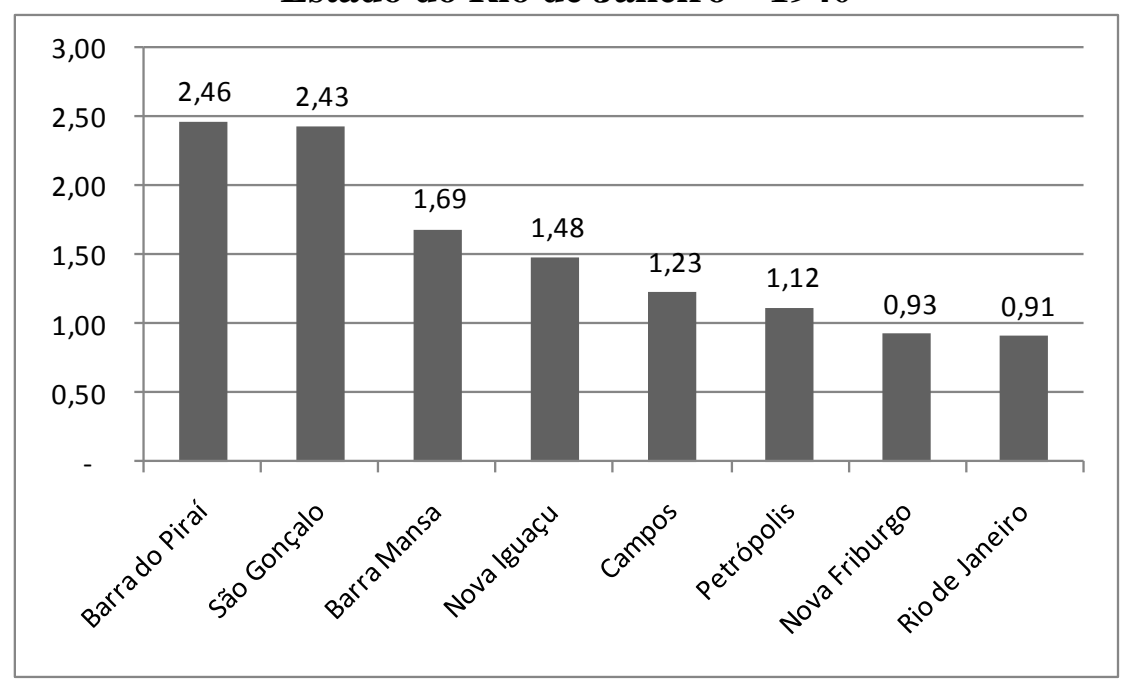

Fonte: Elaboração própria com base nos dados da Tabela 2.

De fato, ao final dos anos 1930, São Gonçalo contava com 95 estabelecimentos industriais (IBGE, Censos Econômicos), alguns dos quais respondendo por recordes invejáveis: além da já citada maior oficina de laminação da América Latina, a Cia de Cimentos Portland viria a se tornar a maior fornecedora de cimento para o governo federal $(O$ São Gonçalo, 18/07/48).

Existem ainda alguns indícios de que a indústria gonçalense guardava algum grau de complementaridade com a niteroiense - e talvez neste sentido seja possível apontar

\footnotetext{
${ }^{6}$ No ranking da produtividade, a indústria gonçalense perdia apenas para Barra Mansa, cujo produto industrial era bem inferior ao gonçalense, cerca de 1/3.
} 
pecualiaridades no processo de industrialização gonçalense em comparação, por exemplo, com municípios da Baixada Fluminense que fazem fronteira com o Rio de Janeiro. A economia niteroiense, embora longe de ser tão pujante quanto à do Distrito Federal, tinha importância significativa enquanto capital do antigo Estado do Rio de Janeiro. O espaço exíguo do território niteroiense fazia de São Gonçalo o caminho natural para a expansão industrial. De fato, a proximidade com a capital enquanto fator de estímulo à atividade industrial gonçalense pode ser confirmada pelo simples fato de que o distrito industrial de Neves, onde se concentrava boa parte das indústrias gonçalenses, fazia fronteira com Niterói, funcionando até hoje como uma das mais importantes portas de entrada para São Gonçalo.

Além disso, São Gonçalo contava ainda com disponibilidade de áreas planas, no total de $45 \mathrm{~km}^{2}$, consideradas adequadas para a atividade industrial (Federação das Indústrias do Estado da Guanabara, 1969), e os terrenos eram, em média, mais baratos do que os disponíveis em Niterói (IBGE, 1957). A abundância de matérias-primas que atraíssem indústrias extrativas e de transformação de produtos minerais não metálicos também pode ser citada entre os fatores capazes de atrair a atividade industrial durante o os anos 1940/50.

Finalmente, a disponibilidade de mão de obra aparece como outro fator explicativo. A presença de mão de obra era condicionada pela existência de pequenas propriedades rurais situadas em torno de Niterói e de São Gonçalo. Além disso,

(...) o cômputo de pequenas fábricas de brinquedos, doces, forjas, faz supor que houve um período de indústrias domiciliares como fase preliminar a uma maior industrialização e urbanização da área rural. (...) Na antiga zona rural as indústrias encontravam mão de obra mais dócil e mais barata que o proletariado já organizado do Rio de Janeiro [Capital Federal]. (IBGE, 1957:221)

Assim, o parque industrial gonçalense, pela sua dimensão, diversificação e produtividade, atiçava sentimentos ufanistas e levou o município a ser chamado de Manchester Fluminense:

O parque industrial de São Gonçalo, considerado o mais importante do Estado do Rio e dos mais notáveis de todo o Brasil, coloca o Município em posição de grande destaque entre as demais regiões industriais do país.

Bem merecida é a denominação "Manchester Fluminense" dada à cidade. (Palmier, 1940:121)

Do jornal $O$ São Gonçalo, anunciando a construção do novo edifício do Fórum: “(...) estamos todos de parabéns, quando é certo que o início das obras do edifício do Fórum, para 
conclusão em breve prazo, também corresponde a uma nova era de realizações da Manchester Fluminense (...)" (O São Gonçalo, 03/04/49:1). ${ }^{7}$

A participação de São Gonçalo no produto industrial estadual, no entanto, se reduziu substancialmente entre 1940 e 1950 (Tabela 2), perdendo posição relativa e ficando atrás de Barra Mansa (que passa a abrigar a CSN no distrito de Volta Redonda, que viria a emanciparse $\log$ o em seguida), Niterói e Petrópolis - além do Rio de Janeiro, se for levada em consideração a atual configuração territoral do Estado, como faz a Tabela 2. O mesmo não acontece com o emprego industrial, cuja participação relativa de São Gonçalo aumenta em quase um ponto percentual. Isto evidencia outro aspecto do declínio industrial, que é a queda da produtividade de sua indústria.

A análise da composição do emprego industrial fornece pistas do que ocorreu em São Gonçalo. Em 1950, cerca de 58\% da mão de obra ocupada no setor industrial estava nos ramos de produtos minerais não metálicos e de metalurgia, seguidos de alimentos e bebidas, produtos químicos/farmacêuticos, e produtos de borracha/fumo/couros/peles. A cadeia industrial era concentrada nesses cinco setores, e faltavam elos da cadeia, como indústria mecânica, material elétrico e de comunicações, transporte, e também indústrias chamadas tradicionais, como têxtil e calçados. É evidente que, por se tratar apenas de um município, isto não parece tão grave à primeira vista, já que a complementaridade da cadeia pode ser obtida nas vizinhanças. Entretanto, municípios cujas indústrias viriam, mais tarde, a ultrapassar a indústria gonçalense, como Niterói e Duque de Caxias, possuíam maior diversificação (Tabela 3).

\section{O declínio da indústria gonçalense}

É importante fazer algumas observações sobre o que definimos por declínio da indústria gonçalense. A caracterização do declínio não pressupõe necessariamente crescimento negativo do produto ou do emprego industrial, bastando apenas que as variáveis utilizadas para dimensionar a sua indústria registrem crescimento abaixo da média estadual, o que implica perda de participação relativa. Produtividade declinante também é um indicador importante, porque sinaliza baixa capacidade de competir e, portanto, fôlego limitado.

Importante também é caracterizar a indústria gonçalense da fase do auge como resultado de esforços privados, típica do que a literatura econômica chama de industrialização

\footnotetext{
${ }^{7}$ Foram encontradas outras referências a São Gonçalo como Manchester Fluminense em Shartow (1964:140), na revista Atualidade, n. 193, de 29/09/63, e no Jornal O Globo, de 04/10/98.
} 
espontânea, em que os principais estímulos estatais limitavam-se às isenções fiscais. Em um contexto de ação deliberada do Estado brasileiro para promover a industrialização, a escolha dos municípios que abrigariam as plantas industriais resultantes dos esforços estatais foi determinante para traçar o novo vetor de desenvolvimento industrial fluminense. São Gonçalo ficou fora desta escolha. Além disso, a infraestrutura provida pelo poder público se precarizava sem ser reaparelhada com a rapidez que o desenvolvimento industrial demandava.

Assim, a infraestrutura que outrora parecera adequada para a atração de investimentos industriais se esgotaria, e isto se tornaria evidente com rapidez. Ao longo da década de 1940, a população gonçalense cresceu quase $50 \%$, provavelmente (mas não exclusivamente) atraída pelas oportunidades de trabalho que o desenvolvimento industrial oferecia. Na década de 1960, a população quase dobrou (Tabela 3). 
Tabela 3. Estado do Rio de Janeiro: composição do emprego industrial em municípios selecionados, 1950

\begin{tabular}{|c|c|c|c|c|c|c|c|c|c|c|c|c|c|c|}
\hline Municipios & $\begin{array}{c}\text { Extrativa } \\
\text { mineral }\end{array}$ & $\begin{array}{l}\text { Prod } \\
\text { Minerais } \\
\text { Näo- } \\
\text { Metálicos }\end{array}$ & $\begin{array}{l}\text { Meta- } \\
\text { lúrgica }\end{array}$ & $\begin{array}{l}\text { Mecâ- } \\
\text { nica }\end{array}$ & $\begin{array}{c}\text { Mat } \\
\text { elétrico } \\
\text { e de } \\
\text { comunic }\end{array}$ & $\begin{array}{c}\text { Mat de } \\
\text { transporte }\end{array}$ & $\begin{array}{c}\text { Madeira e } \\
\text { mobiliário }\end{array}$ & $\begin{array}{c}\text { Papel, } \\
\text { papelão, } \\
\text { ed e } \\
\text { gráfica }\end{array}$ & $\begin{array}{l}\text { Borracha, } \\
\text { fumo, } \\
\text { couros, } \\
\text { peles, }\end{array}$ & $\begin{array}{l}\text { Quimica e } \\
\text { prod farm }\end{array}$ & $\begin{array}{c}\text { Têxtil e } \\
\text { calçados }\end{array}$ & $\begin{array}{c}\text { Prod alim, } \\
\text { bebidas }\end{array}$ & $\begin{array}{l}\text { Serv de } \\
\text { caráter } \\
\text { industrial }\end{array}$ & Total \\
\hline Rio de Janeiro & - & 7,07 & 6,92 & 1,17 & 1,84 & 0,19 & 5,49 & 10,30 & 14,30 & 7,71 & 27,28 & 12,13 & 5,60 & 100,00 \\
\hline Niterói & - & 6,68 & 7,94 & 3,78 & 1,11 & 29,70 & 6,12 & 2,60 & 5,64 & 5,28 & 15,21 & 9,85 & 6,09 & 100,00 \\
\hline Petrópolis & - & - & 0,80 & - & - & - & 1,17 & 3,39 & 10,92 & - & 74,32 & 7,02 & 2,37 & 100,00 \\
\hline Campos & - & 5,26 & - & 2,75 & - & - & 0,92 & - & 15,22 & - & 10,15 & 65,71 & - & 100,00 \\
\hline São Gonçalo & 4,22 & 27,84 & 24,65 & - & - & - & - & 1,71 & 11,09 & 13,81 & - & 16,20 & 0,48 & 100,00 \\
\hline Barra Mansa & - & 1,18 & 70,80 & - & - & - & - & - & 6,96 & 10,32 & - & 8,97 & 1,77 & 100,00 \\
\hline Magé & 2,88 & - & - & - & - & - & - & - & 5,99 & - & 90,29 & 0,84 & - & 100,00 \\
\hline Nova Friburgo & - & - & 6,31 & - & - & - & - & - & 13,12 & - & 79,09 & 1,48 & - & 100,00 \\
\hline Duque de Caxias & - & 26,50 & 6,45 & - & - & 38,67 & 0,85 & - & 8,12 & 2,49 & 7,64 & 8,52 & 0,76 & 100,00 \\
\hline Nova Iguaçu & - & 42,04 & 5,85 & - & - & 1,49 & 8,05 & 5,07 & 17,38 & 3,54 & 4,91 & 10,82 & 0,84 & 100,00 \\
\hline Total RJ & 0,39 & 7,55 & 7,68 & 1,09 & 1,29 & 2,37 & 4,25 & 7,96 & 13,29 & 6,38 & 27,07 & 14,31 & 4,50 & 100,00 \\
\hline
\end{tabular}

Fonte: IBGE, Censos Econômicos, 1950. Elaboração própria. 


\section{Tabela 4. São Gonçalo: População residente e taxa de crescimento}

\begin{tabular}{|c|c|c|}
\hline Ano & $\begin{array}{c}\text { População (n. } \\
\text { hab.) }\end{array}$ & Tx de crescimento (\%) \\
\hline 1940 & 85.521 & \\
\hline 1950 & 127.276 & 48,82 \\
\hline 1960 & 247.754 & 94,66 \\
\hline 1970 & 430.271 & 73,67 \\
\hline 1980 & 615.352 & 43,01 \\
\hline 1991 & 779.832 & 26,73 \\
\hline 2000 & 891.120 & 14,27 \\
\hline
\end{tabular}

Fonte: IBGE e Fundação CIDE. Taxa de variação calculada pelos autores.

Os pequenos portos do litoral do município, que no passado serviam ao transporte da produção agrícola, não comportavam a escala da produção industrial e muitos já haviam encerrado suas atividades. Das três linhas férreas que cortavam o município, uma delas - a Industrial - resultou de investimentos da Cia de Cimentos Portland, privada (Palmier, 1940). ${ }^{8}$

Já as dificuldades no tocante ao abastecimento de água eram reconhecidos pelo governo do estado, conforme demonstra a mensagens enviadas à Assembleia Legislativa já em 1949: “O problema exige solução urgente” (Governo do Estado do Rio de Janeiro, 1949:131). Em outra mensagem, alguns anos depois, a solução para o referido problema ainda encontrava-se em estudos pelo governo estadual:

(...) a [atividade] de maior destaque [da Comissão de Águas e Esgotos] foi realizada para a solução do problema de abastecimento de água em Niterói e São Gonçalo, cuja situação de verdadeira calamidade pública já foi por nós relatada em todas as mensagens anteriores. (Governo do Estado do Rio de Janeiro, 1954:260)

Além disso, não existia em São Gonçalo uma elite industrial suficientemente forte para dar prosseguimento ao seu desenvolvimento industrial. De fato, as principais indústrias locais, como a Cia Brasileira de Usinas Metalúrgicas, a Eletroquímica Fluminense, a Fiat Lux e a Cia Nacional de Cimentos Portland tinham suas sedes no antigo Estado da Guanabara (Federação das Indústrias do Estado da Guanabara, 1969), e se instalaram em São Gonçalo por conta dos incentivos fiscais e dos fatores locacionais ali presentes.

\footnotetext{
${ }^{8}$ As outras duas eram a Maricá e a Leopoldina.
} 
É possível perceber ainda que os anos 1940/50 representaram um ponto de inflexão na indústria gonçalense. Embora em 1940 São Gonçalo tenha alcançado o nível máximo de participação no produto industrial estadual, registrou, em 1950, um aumento na participação no nível de empregos no setor a uma taxa superior à média estadual. Este crescimento, no entanto, parece ter chegado a um ponto de esgotamento: nos anos seguintes, a indústria gonçalense segue, a partir daí, uma trajetória inexorável de perda de participação relativa, ora crescendo a taxas inferiores à média estadual, ora decrescendo, sem jamais retomar à posição de destaque dos períodos de Manchester.

A insuficiência de infraestrutura citada acima pode ser apontada como uma das causas deste declínio. Por ser tradicionalmente suprida pelo Estado, o problema remete a outra questão maior, o padrão de intervenção estatal sobre o território fluminense. Sobre a esfera federal, pesa o fato de São Gonçalo jamais ter sido escolhido para sediar os grandes projetos industrializantes tocados pelo governo federal no Estado do Rio. Sobre as esferas estadual e municipal recaem o peso da já citada infraestrutura precária. O jornal $O$ São Gonçalo externava os ressentimentos quanto a isto: "É verdade dura, mas é verdade que o que mais se observa na evolução material e social de São Gonçalo deve-se à iniciativa particular” (O São Gonçalo, 27/02/49:1).

De fato, já na passagem dos anos 1940 para os anos 1950 as dificuldades econômicas pareciam mais evidentes, conforme denunciava o jornal em outra edição:

(...) De cinco anos para cá, o surto de progresso, em nosso meio, é dos mais sensíveis e elogiáveis, pena que o poder público, sempre mais de perto interessado na marcha evolutiva do soerguimento material da Comuna, seja o emprestador do menor coeficiente na medida dessa grandeza.

Mas, a iniciativa particular que tem sabido dignificar os nossos foros de civilização, jamais tem deixado de ser a única alavanca mágica da evolução que se admira a todo instante, em nossa admirável COBAIA - esta hospitaleira São Gonçalo! (...). (O São Gonçalo, 16/10/49:1)

Aqui, é importante ressaltar que, tipicamente, a maior parte dos investimentos voltados à industrialização cabia ao governo federal, enquanto aos governos estaduais parecia mais apropriado prover alguma infraestrutura necessária ao desenvolvimento das atividades econômicas (não necessariamente industrial). Especificamente no caso do Estado do Rio, este demorou a reconhecer a necessidade de uma política específica voltada para este fim: a Secretaria de Agricultura, por exemplo, somente foi criada em 
1939, conforme referência feita pelo governador Macedo Soares em mensagem enviada à Assembleia Legislativa em 1947:

No Estado do Rio de Janeiro a Secretaria de Agricultura só foi criada em 1939; até então as funções que lhe competem eram exercidas por um departamento da Secretaria de Viação e Obras Públicas. Os recursos atribuídos à Secretaria de Agricultura têm sido, no entanto, exíguos. (...) É intuito do Governo dar à Secretaria de Agricultura elementos que lhe permitam desdobrar sua ação, de acordo com um programa que está sendo cuidadosamente elaborado. (Rio de Janeiro (Estado), 1947:47)

Vinculado à Secretaria de Agricultura estava a Divisão do Trabalho, Indústria e Comércio, cujas atividades, segundo a própria mensagem, resumiam-se à fiscalização das leis trabalhistas.

Somente em 1951 o governo estadual parecia reconhecer a importância do estímulo específico à atividade industrial, conforme a mensagem por ele enviada à Assembleia Legislativa em 1951:

Todo o Estado do Rio, a bem dizer, deve ser aproveitado com esse objetivo [a industrialização], desde que se atendam a certos problemas marginais. Dispondo de abundante mão de obra, por ser das unidades federativas de maior densidade demográfica, não lhe faltando matérias-primas nem potencial hidráulico, tem a vantagem de estar colocado próximo de grandes mercados, facilmente acessíveis, pois que se encontram nas pontas das maiores vias de transporte do país, que lhe atravessam o território. A outra parte dele pode, ajudado por um plano racional de obras públicas, ligar-se ao referido sistema de estradas, por onde escoem seus produtos manufaturados. (Rio de Janeiro (Estado), 1951:41)

Nesta mensagem, pela primeira vez, o governo estadual parece ter, enfim, um programa de estímulo à atividade industrial e, mais ainda, mostra-se preocupado com a questão regional no Estado do Rio, ao menos na retórica: "Retirar as indústrias das cidades e localizá-las no interior - eis um grande passo para um reajustamento dos padrões de vida e, simultaneamente, para o aperfeiçoamento e desenvolvimento das atividades agrárias" (Rio de Janeiro (Estado), 1951:42).

Em termos práticos, no entanto, tem-se apenas a confirmação da região do Médio Paraíba como um importante parque industrial que aos poucos foi se expandindo em função da criação da CSN, investimento oriundo do governo federal.

Embora não seja objeto deste trabalho analisar os aspectos políticos que certamente envolviam as decisões econômicas tomadas por parte dos governos federal e 
estadual, o fato é que, objetivamente, poucas eram as ações governamentais efetivamente voltadas para estimular a indústria fluminense. O debate acerca da necessidade de maior participação do governo estadual no estímulo à industrialização, seja de forma direta ou pelo provimento de infraestrutura, ainda ocorria no final dos anos 1950. Eleito governador em 1958, Roberto da Silveira afirmava, em entrevista, "que [pretendia] instalar em nosso Estado uma fábrica de peças de ônibus elétricos, cuidando, outrossim, de aumentar a produção de energia elétrica para facilitar o desenvolvimento da indústria" (O São Gonçalo, 01/01/59:1).

$\mathrm{E}$, do ponto de vista do governo municipal, ainda que o raio de alcance de suas ações no sentido de estimular as atividades econômicas fosse menor, elas obtinham algum resultado neste sentido, ao menos na esfera tributária: "um depósito de cigarros em Niterói paga mais imposto de localização do que uma grande indústria em São Gonçalo, como a Hime, etc., para não citar outras de menor importância" ( $O$ São Gonçalo, 04/01/59:1). Não se sabe, entretanto, se este diferencial consistia em uma pouco provável ação deliberada do governo municipal de estimular a sua economia ou, o mais provável, se a legislação tributária municipal era falha. Esta última hipótese é tratada como mais provável porque o diferencial das taxas é debatido no âmbito da Reforma do Código Tributário municipal, conforme anuncia a reportagem: "No caso do comércio e indústria, segundo pudemos apurar na Prefeitura, a desproporção para menos do nosso Código de Posturas com os dos Municípios de Niterói, Magé e Itaboraí que são nossos vizinhos é particularmente grande" (O São Gonçalo, 04/01/59:1).

Os mais importantes eventos econômicos e políticos que se sucederam continuaram sem ter São Gonçalo como beneficiário. De natureza econômica, pode-se citar a implantação da Refinaria de Duque de Caxias (Reduc), os investimentos de expansão da CSN na já emancipada Volta Redonda e, já no limiar dos anos 1970, a política de estímulo à construção naval, que teve Niterói e Angra como maiores beneficiadas. De natureza política, os principais acontecimentos foram transferência da capital federal para Brasília, com a transformação do antigo Distrito Federal em Estado da Guanabara, e, mais tarde, a fusão da Guanabara com o Rio de Janeiro, com Niterói perdendo o status de capital estadual.

Assim, Duque de Caxias e Volta Redonda, municípios onde a ação estatal se verifica com maior clareza, passam a deter, respectivamente, $16 \%$ e 9,5\% do produto industrial estadual em 1975, de acordo com a Tabela 5. A produção industrial gonçalense já era superada também pela de Nova Iguaçu, Barra Mansa, Petrópolis e 
Niterói, além do Rio de Janeiro, os dois primeiros considerados casos clássicos de efeitos aglomerativos por ocasião da Reduc e da CSN.

Tabela 4. Produto e emprego industrial (\%) por município do Estado do Rio de Janeiro (municípios selecionados) - 1975 e 2000

\begin{tabular}{|c|c|c|c|c|c|c|c|c|}
\hline & \multicolumn{4}{|l|}{ Produto } & \multicolumn{4}{|l|}{ Emprego } \\
\hline & 1975 & & 2000 & & 1975 & & 2000 & \\
\hline 1 & Rio de Janeiro & 52,54 & Rio de Janeiro & 51,06 & Rio de Janeiro & 62,35 & Rio de Janeiro & 51,46 \\
\hline 2 & Duque de Caxias & 16,17 & Volta Redonda & 10,41 & Duque de Caxias & 4,70 & Duque de Caxias & 5,41 \\
\hline 3 & Volta Redonda & 9,44 & Duque de Caxias & 9,04 & Petrópolis & 3,83 & São Gonçalo & 3,95 \\
\hline 4 & Niterói & 2,84 & Resende & 5,86 & Niterói & 3,69 & Volta Redonda & 3,55 \\
\hline 5 & Nova Iguaçu & 2,65 & São Gonçalo & 2,39 & Volta Redonda & 2,96 & Petrópolis & 3,45 \\
\hline 6 & Barra Mansa & 2,21 & Barra Mansa & 1,66 & Nova Iguaçu & 2,82 & Nova Friburgo & 3,43 \\
\hline 7 & Petrópolis & 2,07 & Niterói & 1,65 & São Gonçalo & 2,25 & Nova Iguaçu & 3,25 \\
\hline 8 & $\underline{\text { São Gonçalo }}$ & 1,66 & Nova Iguaçu & 1,60 & Nova Friburgo & 1,90 & Niterói & 2,51 \\
\hline 9 & Campos & 1,22 & Belford Roxo & 1,52 & Campos & 1,85 & Macaé & 2,09 \\
\hline \multirow[t]{2}{*}{10} & Resende & 1,06 & Petrópolis & 1,35 & Barra Mansa & 1,50 & Campos & 1,70 \\
\hline & Total & 91,86 & Total & 86,54 & & 87,85 & & 80,8 \\
\hline
\end{tabular}

Fonte: IBGE/Censo Industrial para os dados de 1975; Fundação CIDE para o produto industrial em 2000 e MTE/RAIS para o emprego em 2000.

Ao longo da década de 1970, o fenômeno do declínio industrial gonçalense ganharia novas características, agora de perda de indústrias. "Na década de setenta, a Hime reorientou suas estruturas (...) começando o seu deslocamento para o distrito industrial de Nova Iguaçu, onde teria condições de conjugar modernização tecnológica com expansão de capacidade" (IEPS, 1983:183). Com relação à possibilidade de expansão de capacidade, é razoável supor que em São Gonçalo isso seria inviável. O bairro de Neves, onde estava localizada, outrora estritamente industrial, passou a tornarse também um bairro residencial em função do crescimento desordenado do município. O espaço tornou-se exíguo, o que certamente impossibilitou a sua expansão, e certamente a unidade de Nova Iguaçu atendia melhor às suas necessidades de crescimento. E considerando-se que a Hime era a maior metalúrgica de São Gonçalo, os efeitos de sua reestruturação foram significativos. Assim, São Gonçalo, que respondia por $8,5 \%$ dos empregos da metalurgia de todo o estado em 1950 (era o $3^{\circ}$ maior, perdendo apenas para a capital e para Barra Mansa), chega em 1975 respondendo por apenas $3,5 \%$.

Além disso, o parque metalúrgico gonçalense não parecia estar muito articulado com a indústria de construção naval presente em Niterói. De fato, os anos 1970 
corresponderam ao auge do setor (Grassi, 1995), mas somente no ano de 1978 é que São Gonçalo passaria a se beneficiar dos efeitos de encadeamento da indústria naval, vindo a abrigar a Metalúrgica Sinel que, conforme noticiava o jornal $O$ Fluminense em 28/05/78, “atenderá a todos os estaleiros com equipamentos complementares para navios (...) com capacidade para fornecimento de 200 toneladas por mês de ferro beneficiado, utilizando cerca de 50 operários especializados”. A crise do setor naval viria pouco tempo depois.

O parque químico gonçalense também enfrentaria as agruras da infraestrutura insuficiente. A principal empresa do setor, a Eletroquímica Fluminense, deparava-se no período com o elevado preço da energia elétrica utilizada pela empresa, considerado caro para os padrões internacionais: de 5 a 10 vezes mais do que o cobrado nos países industrializados (CNI, 1967). Além disso, um forte temporal que se abateu sobre o estado levou a empresa a suspender suas atividades em janeiro de $1966 .{ }^{9}$

Outra grande indústria do setor de extração, a Cia de Cimentos Portland, teve suas atividades encerradas nos anos 1960 por um motivo bastante inusitado: durante suas atividades, acabou por perfurar um aquífero que teria inundado toda a área destinada à exploração de matéria-prima e inviabilizado em definitivo suas atividades (cf Nascimento e Ribeiro, 2000). A empresa, que possuía filial em Cantagalo (Região Serrana) transferiu-se em definitivo para lá. No local existe hoje um lago, conhecido como Lago São José ou Lago Azul.

As décadas de 1970 e 1980 ainda marcariam São Gonçalo por dois eventos. O primeiro foi a construção da ponte Presidente Costa e Silva, ligando a nova e a antiga capital (Rio e Niterói). A redução da distância entre a cidade do Rio de Janeiro e os municípios do outro lado da Baía de Guanabara poderia significar um fator de atração para novas indústrias na região, especialmente para Niterói e São Gonçalo. São Gonçalo recebeu ainda a construção do trecho da rodovia federal BR-101, ligando Niterói a Manilha, e cortando quase todo o município de São Gonçalo, inclusive o agora esvaziado distrito industrial de Neves. A construção da rodovia vem a servir como solução para alguns problemas de infraestrutura, especialmente aqueles relacionados ao tráfego e escoamento da produção:

\footnotetext{
${ }^{9}$ Não foi possível saber se a suspensão das atividades da Eletroquímica Fluminense por ocasião do temporal foi temporária ou definitiva. O jornal $O$ Fluminense, em 30/01/66, noticiava na página 7 "a invasão de dezenas de fábricas pelas águas, que danificaram máquinas e acabaram estoques, paralisando indústrias". O caráter genérico da notícia se estendia pelos dias seguintes. Contudo, a data do relatório da CNI - 1967 - sugere fortemente interrupção definitiva das atividades da empresa.
} 
Com a inauguração da Ponte Presidente Costa e Silva (RioNiterói) em 1974, houve a necessidade de se fazer o escoamento do eixo Rio-Niterói em direção à Região dos Lagos e Norte Fluminense, concentrando também o trajeto que demandava dos estados da Região Nordeste e o fluxo que se dirigia à Região Serrana e Cento-Norte Fluminense. Surge então a rodovia Niterói-Manilha, para sanar os problemas de tráfego e escoamento da produção, tanto para o Rio de Janeiro quanto para São Gonçalo e municípios vizinhos. (Almeida, 2001:23)

Contudo, o que deveria servir como fator de atração e estímulo à economia local contribuiu para o maior crescimento populacional sem ordenamento: em vez de indústrias, há hoje um grande número de favelas às margens da rodovia. Cortando também boa parte dos $22 \mathrm{~km}$ de litoral do município, a rodovia causou ainda problemas ambientais, degradando os manguezais que até então encontravam-se preservados e abundantes (Almeida, 2001). O que, em um primeiro momento, poderia constituir mera preocupação ambiental, tornar-se-ia em seguida um entrave econômico na medida em que os problemas ambientais também têm se constituído economias de desaglomeração em algumas regiões do país (Diniz, 1991).

Nos anos 1980 e 1990 prossegue o movimento de desindustrialização: a Hime transfere-se definitivamente para Nova Iguaçu, ficando a Comercial Gerdau em seu lugar. A empresa, contudo, fica por poucos anos, transferindo suas atividades para o bairro de Santa Cruz, Zona Oeste do Município do Rio de Janeiro. Segundo um funcionário da empresa,

(...) a transferência da fábrica para a Zona Oeste dava início a um grande investimento feito pela empresa na casa de centenas de milhões. Em São Gonçalo eram produzidas, até o início da década de 90, dez mil toneladas por mês com 130 homens. Com o novo sistema, já instalado em Santa Cruz, (...) produz 40 mil toneladas/mês com apenas 50 homens. (Nascimento e Ribeiro, 2000:27)

Já a Cia de Fósforos Fiat Lux encerrou suas atividades em São Gonçalo em 1983, transferindo sua produção para a filial de Curitiba ( $O$ Fluminense, 22/09/83), dando lugar a uma filial do hipermercado Carrefour aproximadamente uma década depois. 


\section{Considerações finais}

O processo de desenvolvimento industrial ocorrido em São Gonçalo na primeira metade do século XX teve como principal característica o fato de ser induzido pelo setor privado, estando as políticas de desenvolvimento industrial restritas aos incentivos fiscais. Com pouco fôlego, em pouco tempo os investimentos industriais deram sinais de esgotamento e já no início da segunda metade do século deu-se início ao processo de esvaziamento industrial.

A fase de declínio industrial tem causas diversas. A ausência de uma burguesia industrial local (já que as principais indústrias instaladas eram de outros estados) comprometida com os interesses do município constitui uma delas. Entretanto, a baixa capacidade desses investimentos privados em gerar novo fôlego pode ser apontada como segunda causa.

A atuação do Estado (nas três esferas de governo) surge como uma terceira causa, e talvez seja a mais importante entre todas. A infraestrutura precária existente em São Gonçalo aparece como causa do desinvestimento de várias indústrias do município. Além disso, as escolhas de outros municípios do interior do Estado do Rio de Janeiro para abrigar importantes investimentos no âmbito dos projetos desenvolvimentistas tocados pelo Estado brasileiro determinaram novos vetores de expansão industrial fluminense, dos quais São Gonçalo não fez parte.

Somente seis décadas depois do título de Manchester Fluminense é que novas perspectivas de desenvolvimento industrial são abertas para o município: a escolha do município de Itaboraí para abrigar o Complexo Petroquímico do Estado do Rio de Janeiro (Comperj), tendo São Gonçalo como um dos municípios de influência, ${ }^{10}$ pode transformar em novo vetor de expansão industrial a microrregião onde o município está localizado. Tais perspectivas constituem importante agenda de pesquisa e devem levar em consideração a proximidade, a disponibilidade de mão de obra qualificada, infraestrutura e planejamento urbano de modo a evitar um novo ciclo de crescimento desordenado.

\footnotetext{
${ }^{10}$ Os outros são: Cachoeiras de Macacu, Casimiro de Abreu, Guapimirim, Niterói, Maricá, Magé, Rio Bonito, Silva Jardim e Tanguá.
} 


\section{Referências bibliográficas}

ALMEIDA, G. C. Transformações sócio-espaciais no litoral gonçalense decorrentes da construção da Rodovia BR-101 (Niterói-Manilha). Monografia (Bacharelado em Geografia). Niterói: UFF, 2001.

ARAUJO, V. L. Um estado fundido: contribuições para o debate em torno da "desfusão" dos estados do Rio de Janeiro e Guanabara. Revista Econômica, v. 7, n. 1, pp. 5-33, Rio de Janeiro, 2005.

BRAGA, Maria Nelma Carvalho. O Município de São Gonçalo e a sua história. São Gonçalo: Edição Independente, 1997.

CANO, W. Raízes da concentração industrial em São Paulo. Rio de Janeiro: DIFEL, 1977.

CONFEDERAÇÃO NACIONAL DA INDÚSTRIA (CNI) et all. Levantamento SócioEconômico do Estado do Rio de Janeiro: Documentos Setoriais. Rio de Janeiro, 1967.

DINIZ, C. C. Dinâmica regional da indústria no Brasil: início de desconcentração, risco de reconcentração. Tese ao concurso de Professor Titular. Belo Horizonte: FACE/UFMG, 1991.

FEDERAÇÃO DAS INDÚSTRIAS DO ESTADO DA GUANABARA (FIEGA). A fusão da cidade do Rio de Janeiro com o Estado do Rio. Estado da Guanabara, Julho de 1969.

\section{GOVERNO DO ESTADO DO RIO DE JANEIRO (1949 E 1954)}

GRASSI, Robson Antonio. A indústria naval brasileira no período 1958-1994: uma análise histórica de sua crise atual e das perspectivas de mudança, a partir do conceito estrutura de competitividade. Dissertação de Mestrado em Economia. Niterói: UFF, 1995.

INSTITUTO BRASILEIRO DE GEOGRAFIA E ESTATÍSTICA (IBGE). Anuário Geográfico do Estado do Rio de Janeiro. Rio de Janeiro, 1957.

Censos Econômicos dos Municípios - indústria, comércio e serviços. Rio de Janeiro: IBGE, Vários anos. 
INSTITUTO DE ESTUDOS POLÍTICOS E SOCIAIS (IEPS). Projeto Pró-Rio. Problemas e potencialidades do Estado do Rio de Janeiro. Relatório Geral, $2^{\circ}$ volume, seção IV. Rio de Janeiro, 1983.

Jornal O São Gonçalo. São Gonçalo, RJ. Vários anos.

Jornal O Fluminense. Niterói, RJ. Vários anos.

LESSA, C. A estratégia de desenvolvimento: sonho e fracasso. Brasília (DF): Funcep, 1998.

MELO, H. P. \& CONSIDERA, C. M. Industrialização fluminense: 1930/1980. Revista do Rio de Janeiro, nº 3, Niterói: EdUFF, ago. 1986.

MELO, H. P. \& ALVEAL, C. A trajetória desigual do desenvolvimento econômico fluminense. In: XVI ENCONTRO NACIONAL DE ECONOMIA (Anpec), Belo Horizonte, 1988.

NASCIMENTO, F. A. \& RIBEIRO, J. L. F. São Gonçalo industrial - uma análise do processo de industrialização e desindustrialização do município de São Gonçalo no século XX. In: VI CURSO DE HISTÓRIA DE SÃO GONÇALO. São Gonçalo: Instituto Cultural Brasil-Estados Unidos, 2000.

PALMIER, Luiz. São Gonçalo Cinqüentenário. Rio de Janeiro: IBGE, 1940.

OLIVEIRA JUNIOR, Desiderio Luiz de (Org). Indicador de Leis, Decretos, Deliberações e mais actos relativos ao período de 1 de Janeiro de 1922 a 31 de Dezembro de 1925. Rio de Janeiro: Typog. Do Jornal do Commercio, 1929.

PIGNATON, A. A. G. Origens da industrialização no Rio de Janeiro. Dados, Revista do Instituto Universitário de Pesquisas do Rio de Janeiro, n. 15, pp. 139-154, 1977.

PROCHNIK, Victor. As possibilidades das empresas nacionais: o caso do imento. In: XII ENCONTRO NACIONAL DE ECONOMIA (Anpec), São Paulo: FEA/USP, 1984.

RIO DE JANEIRO (Estado). Mensagem apresentada à Assembléia Legislativa do Estado do Rio de Janeiro no dia $1^{\circ}$ de outubro de 1929 pelo presidente Manuel de Mattos Duarte Silva. S/L, 1929. 
RIO DE JANEIRO (Estado). Mensagem apresentada à Assembléia Legislativa do Estado do Rio de Janeiro no dia $1^{\circ}$ de outubro de 1930 pelo presidente Manuel de Mattos Duarte Silva. S/L, 1930.

RIO DE JANEIRO (Estado). Mensagem apresentada à Assembléia Constituinte do Estado do Rio de Janeiro pelo interventor Ary Parreiras. Niterói: Oficinas Gráphicas do Diário Oficial, 1935.

RIO DE JANEIRO (Estado). Primeira Mensagem do Governador do Estado do Rio de Janeiro, Cel. Edmundo de Macedo Soares e Silva, à Assembléia Legislativa do Estado do Rio de Janeiro. S/L, 1947.

RIO DE JANEIRO (Estado). Mensagem apresentada pelo Governador Edmundo de Macedo Soares e Silva à Assembléia Legislativa do Estado do Rio de Janeiro, a 15 de março de 1949. Niterói: Imprensa Estadual - Divisão de Obras, 1949.

RIO DE JANEIRO (Estado). Mensagem à Assembléia Legislativa apresentada pelo governador por ocasião da abertura da sessão legislativa de 1951. S/ Local, 1951.

RIO DE JANEIRO (Estado). Mensagem à Assembléia Legislativa apresentada pelo governador por ocasião da abertura da sessão legislativa de 1954. S/ Local, 1954.

SARTHOW, Carlos. Passado e presente da Baía de Guanabara - 1565-1965. Rio de Janeiro: Livraria Freitas Bastos S.A., 1964.

VARSANO, Ricardo. A evolução do sistema tributário brasileiro ao longo do século: anotações e reflexões para futuras reformas. Revista Pesquisa e Planejamento Econômico, vol. 27, n. 1, 1997. 